\title{
Bipolar Disorders: Antipsychotic Drug Therapy of Aripiprazole an Open Label Study
}

Amycus Alecto *, Alberto Benussi.

Department of Neurophysiology, Iran

* Corresponding Author: Amycus Alecto.Department of Neurophysiology, Iran.

Received date: October 04, 2018; Accepted date: October 20, 2018; Published date: November 03, 2018.

Citation for this Article: Amycus Alecto, Bipolar Disorders: Antipsychotic Drug Therapy of Aripiprazole an Open Label Study, J Neuroscience and Neurological Surgery. Doi:10.31579/2578-8868/156

Copyright : (C) 2018 Amycus Alecto. This is an open-access article distributed under the terms of The Creative Commons Attribution License, which permits unrestricted use, distribution, and reproduction in any medium, provided the original author and source are credited.

\section{Abstract}

Patients with bipolar disorder are exceptionally challenging to manage because of the dynamic, chronic, and fluctuating nature of their disease. Typically, the symptoms of bipolar disorder first appear in adolescence or early adulthood, and are repeated over the patient's lifetime, expressed as unpredictable recurrences of hypomanic/manic or depressive episodes. The lifetime prevalence of bipolar disorder in adults is reported to be approximately 4\%, and its management was estimated to cost the US healthcare system in 2009 \$150 billion in combined direct and indirect costs.

\section{Keywords}

Bipolar, Diagnosis, Treatment, Aripiprazole.

\section{Introduction}

Bipolar spectrum disorders are a major public health problem, with estimates of lifetime prevalence in the general population of the United States at 3.9 percent,with a range from 1.5 to 6.0 percent.Bipolar disorder is also associated with significant mortality risk, with approximately 25 percent of patients attempting suicide and 11 percent of patients completing. Furthermore, inadequate treatment and service structure causes high rates of jailing for bipolar patients.Bipolar depression is still undertreated, too, with patients suffering such symptoms 31.9 percent of the time over nearly 13 years.

More pharmacologic options are now available, and psychoeducation, self-help, and psychotherapy (individual, couple, and family) interventions are frequently utilized.The Depression and Bipolar Support Alliance has taken a leading role in educating patients, their families, medical professionals, mental health professionals, and the public at large about manic-depressive illness. The National Alliance of the Mentally Ill (NAMI) has also sought information by surveying family members about utilization and value of mental health services.

\section{Epidemiology}

Bipolar I disorder starts on average at 18 years and bipolar II disorder at 22 years.A community study using the Mood Disorder Questionnaire (MDQ) revealed a prevalence of 3.7 percent.The National Comorbidity Study showed onset typically between 18 and 44, with higher rates between 18 and 34 than 35 and 54. ${ }^{1}$ In a survey of members of the DBSA, more than half of the patients did not seek care for five years and the correct diagnosis was not made until an average of eight years after they first sought treatment.

Cognitive processing is often impaired in bipolar patients, even in euthymic patients.Executive function, visulospatial, memory, verbal fluency, and attentional deficits have been noted. This may be a primary feature of bipolar disorder, secondary to other dysregulation (e.g., insomnia) or secondary to comorbid conditions (e.g., substance use). Cognitive assessment is underutilized in assessing medication side effects, the return to the outpatient sector from inpatient, and employing vocational rehabilitation in preparation for work.

\section{Assessment}

The evaluation of a bipolar patient involves a number of important clinical and psychosocial issues. The primary tool is the neuropsychiatric assessment with the history and physical examination. Brief histories (less than 30 minutes) may be a liability, due to the complexity of the mood course in patients not already diagnosed. Collateral information is required in most cases from family, friends, or prior places of treatment. A delineation of episodic versus chronic symptoms is helpful, except with patients with cycling of mood day-to-day, in a mixed episode, or otherwise very unstable course. Screening instruments can be used for manic episodes (e.g. Mood Disorder Questionnaire [MDQ]), though they may have more utility in primary care settings. The MDQ has 13 yes/no items, and seven positive answers call for a full clinical evaluation.

\section{Psychosocial treatments for bipolar disorder}

Psychotherapeutic treatments, provided individually or through groups and families, are beneficial to nearly all patients with bipolar disorder and provide the context in which psychiatric management and pharmacotherapy work best.Most patients struggle with psychosocial issues Bipolar inpatients were surveyed about their informational needs in one study, and they requested information about bipolar disorder, how to obtain support, how to manage symptoms (e.g., suicidal ideation, anger), and how to improve interpersonal skills. Economic, interpersonal, and vocational problems may occur for years, even when patients do not suffer recurrence of illness leading to hospitalization.

A summary of psychotherapeutic treatments reveals better outcomes and improved adherence to treatment. Cognitive-behavioral, family-focused psychoeducation (also known as behavioral family management), inpatient family, and group psychotherapy have been studied. Easy access to a primary nurse provider increases outpatient utilization without increasing costs. These interventions bridge the gap between ideal controlled trials and everyday practice, in which patients and families benefit from the increased structure of the interventions.

\section{Mood stabilizers for mania}

Mood stabilizers are the mainstay of treatment for bipolar disorder, regardless of whether the patient's presentation is manic or depressed. 
These medications generally require 1 to 4 weeks at therapeutic doses before their full effects are seen. Approximately 50 to 60 percent of patients will respond sufficiently to a single mood stabilizer,while others may require combined pharmacotherapy.They are commonly used in conjunction with benzodiazepines (anxiety, agitation) and other medications.

\section{Methods}

A nationwide non-interventional study using psychiatrists' and patients' surveys.

\section{Results}

839 patients with bipolar or schizoaffective disorder bipolar type were included. Concordance with the guideline was highest for participation of a psychiatrist in the treatment $(98 \%)$ and for maintenance pharmacotherapy (96\%), but lower for supportive treatment $(73.5 \%)$, use of an emergency plan (70.6\%), psychotherapy (52.2\%), group psychoeducation (47.2\%), and mood monitoring (47\%). Presence of a written treatment plan, a more specialized treatment setting, more years of education, and diagnosis of bipolar I disorder versus bipolar II, bipolar NOS, or schizoaffective disorder were significantly associated with better concordance.

\section{Socio-demographic and illness characteristics}

Five hundred and fifty-five respondents $(66.2 \%)$ were women. The average age was 49.5 years (s.d. 11.2). Five hundred and one out of $833(60.1 \%)$ respondents were married or living together. The mean years of education $(n=837)$ was 16.1 years (s.d. 4.3). Diagnoses were BD I $(\mathrm{n}=551 ; 65.7 \%)$, BD II $(\mathrm{n}=211 ; 25.1 \%)$, BD NOS $(\mathrm{n}=32$;

$3.8 \%)$, and SZA $(\mathrm{n}=45 ; 5.4 \%)$. At least one comorbid psychiatric diagnosis was present in 238 respondents $(28.4 \%)$. The mean duration of illness $(\mathrm{n}=712)$ was 23.8 years (s.d. 12.3). The average age at onset for (hypo) manic symptoms was 30.1 years (s.d. 11.8), and for depressive symptoms 26.1 years (s.d. 11.7). Only nine respondents (1.1\%) experienced one single manic episode, 28 (3.3\%) had two mood episodes, all other 718 respondents $(85.6 \%)$ had three or more mood episodes. Data on total lifetime number of mood episodes were inconclusive or missing in 84 respondents (10\%). Hospital admission because of a mood episode was reported by 532 (63.4\%) respondents. Data on admission were missing in 65 respondents $(7.7 \%)$. Of the respondents, $283(33.7 \%)$ had a first degree relative with bipolar disorder.

\section{Concordance with treatment guideline}

Concordance with the guideline for each treatment modality was as follows: participation of a psychiatrist in 757 of 773 respondents (97.9\%), maintenance pharmacotherapy in 754 of 786 (95.9\%), supportive treatment in 560 of $762(73.5 \%)$, use of an emergency plan in 556 of $787(70.6 \%)$, psychotherapy in 399 of 765 (52.2\%), group psychoeducation in 371 of $786(47.2 \%)$, and mood monitoring in 369 of 785 respondents $(47 \%)$.

In a multiple regression analysis age, absence of psychiatric comorbidity, duration of illness, and whether or not it was asked to involve significant others in the treatment, did not contribute significantly to the model, although the latter almost reached significance. All other factors were significant. The model explained almost $10 \%$ of variance in concordance scores.

\section{Conclusion}

The lifetime management of patients with bipolar disorder is challenging, because of the dynamic, chronic, and fluctuating nature of this disease. The healthcare costs for patients and their caregivers are enormous from psychosocial and economic perspectives. It is incumbent on healthcare professionals to reduce the burden of bipolar disorder. Pharmacologic treatment is the mainstay of treatment for patients with bipolar disorder. Individual atypical antipsychotic medications have been shown to be effective for acute mania/hypomania, for acute depression, and for maintenance treatment (of mania and depression), and have been incorporated into many treatment guidelines.
The diligent selection of a specific agent that takes into account its efficacy in the various phases of bipolar disorder, along with its safety profile, can help to ameliorate the impact of this devastating condition.

\section{References}

1. 1.Merikangas KR, Akiskal HS, Angst J, et al. Lifetime and 12-month prevalence of bipolar spectrum disorder in the National Comorbidity Survey replication. Arch Gen Psychiatry. 2007; 64: 543- 552, Erratum in: Arch Gen Psychiatry. 2007; 64: 1039.

2. Geddes JR, Miklowitz DJ. Treatment of bipolar disorder. Lancet. 2013; 381: 1672- 1682 .

3. American Psychiatric Association. Diagnostic and Statistical Manual of Mental Disorders. DSM-5. 5th ed.Arlington, VA: American Psychiatric Publishing; 2013.

4. Baldessarini RJ, Salvatore P, Khalsa H-M, et al. Morbidity in 303 first-episode bipolar I disorder patients. Bipolar Disord. 2010; 12: 264- 270.

5. Judd LL, Akiskal HS, Schettler PJ, et al. The long-term natural history of the weekly symptomatic status of bipolar I disorder. Arch Gen Psychiatry. 2002; 59: 530- 537.

6. Judd LL, Akiskal HS, Schettler PJ, et al. A prospective investigation of the natural history of the long-term weekly symptomatic status of bipolar II disorder. Arch Gen Psychiatry. 2003; 60: 261- 269.

7. Post RM, Denicoff KD, Leverich GS, et al. Morbidity in 258 bipolar outpatients followed for 1 year with daily prospective ratings on the NIMH life chart method. J Clin Psychiatry. 2003; 64: 680-690.

8. Joffe RT, MacQueen GM, Marriott M, Trevor Young L. A prospective, longitutinal study of percentage of time spent ill in patients with bipolar I or bipolar II disorders. Bipolar Disord. 2004; 6: 62- 66.

9. Paykel ES, Abbott R, Morriss R, et al. Sub-syndromal and syndromal symptoms in the longitudinal course of bipolar disorder. $\mathrm{Br} \mathbf{J}$ Psychiatry. 2006; 189: 118- 123.

10. National Institutes of Health. National Institute of Mental Health. Statistics. Accessed December 1, 2014.

11. Dilsaver SC. An estimate of the minimum economic burden of bipolar I and II disorders in the United States: 2009. J Affect Disord. 2011; 129: 79-83.

12. Williams MD, Shah ND, Wagie AE, et al. Direct costs of bipolar disorder versus other chronic conditions: an employer-based health plan analysis. Psychiatr Serv. 2011; 62: 1073- 1078.

13. Zimmerman M, Galione JN, Chelminski I, et al. Sustained unemployment in psychiatric outpatients with bipolar disorder: frequency and association with demographic variables and comorbid disorders. Bipolar Disord. 2010; 12: 720-726.

14. Peele $\mathrm{PB}, \mathrm{Xu} \mathrm{Y}$, Kupfer DJ. Insurance expenditures on bipolar disorder: clinical and parity implications. Am J Psychiatry. 2003; 160: 1286- 1290 .

15. Geddes JR, Burgess S, Hawton K, et al. Long-term lithium therapy for bipolar disorder: systematic review and meta-analysis of randomized controlled trials. Am J Psychiatry. 2004; 161: 217- 222.

16. Scott J, Colom F. Psychosocial treatments for bipolar disorders. Psychiatr Clin North Am. 2005; 28: 371- 384.

17. Baldessarini RJ, Tondo L, Visioli C. First-episode types in bipolar disorder: predictive associations with later illness. Acta Psychiatr Scand. 2014; 129: 383-392.

18. Daban C, Colom F, Sanchez-Moreno J, et al. Clinical correlates of first-episode polarity in bipolar disorder. Compr Psychiatry. 2006; 47: 433- 437

19. Perugi G, Micheli C, Akiskal HS, et al. Polarity of the first episode, clinical characteristics, and course of manic depressive illness: a systematic retrospective investigation of 320 bipolar I patients. Compr Psychiatry. 2000; 41: 13-18.

20. Suppes T, Leverich GS, Keck PE, Jr, et al. The Stanley Foundation Bipolar Treatment Outcome Network: II. Demographics and illness characteristics of the first 261 patients. J Affect Disord. 2001; 67: 4559 . 